\title{
State of the Art of Micro-CT Applications in Dental Research
}

\author{
Michael V. Swain, Jing Xue* \\ Biomaterial research Laboratory, Faculty of Dentistry, The University of Sydney, Sydney, Australia
}

\begin{abstract}
Michael V. Swain, Jing Xue. State of the Art of Micro-CT Applications in Dental Research. International Journal of Oral Science, 1(4): 177-188, 2009

This review highlights the recent advances in X-ray microcomputed tomography (Micro-CT) applied in dental research. It summarizes Micro-CT applications in measurement of enamel thickness, root canal morphology, evaluation of root canal preparation, craniofacial skeletal
\end{abstract}

structure, micro finite element modeling, dental tissue engineering, mineral density of dental hard tissues and about dental implants. Details of studies in each of these areas are highlighted along with the advantages of Micro-CT, and finally a summary of the future applications of Micro-CT in dental research is given.

Keywords X-ray microcomputed tomography (Micro-CT), dentistry, dental application

Received Sept. 5, 2009; Revision accepted Oct. 30, 2009

\section{Introduction}

Since the invention of X-rays by Roentgen in 1895 , technology has led to a revolution in diagnostic medicine, making it possible to see the inner workings of the body non-invasively (Dunn, 2001). X-ray computed tomography (CT) imaging was first developed in the early 1970s. Since then advanced diagnostic imaging technologies have revolutionized the practice of medicine. Images collected from multiple viewing angles are reconstructed to produce three-dimensional (3D) spatial distribution maps of material density within attenuating materials or tissues such as teeth (Hounsfield, 1973). By comparison, conventional radiography was limited to providing two-dimensional (2D) images that represent the summation of material attenuation along the X-ray path. While clinical CT scanners typically produce images composed of $1 \mathrm{~mm}^{3}$ volume elements (voxels), $\mathrm{X}$-ray microcomputed tomography (Micro-CT or $\mu \mathrm{CT}$ ) systems developed in the early 1980s had much better spatial resolution, producing voxels in the range of $5-50 \mu \mathrm{m}$, or approximately $1,000,000$ times smaller in volume than CT voxels (Feldkamp et al., 1989; Kuhn et al., 1990). Early Micro-CT scanners were custom-built and not widely available. Compact commercial systems are now available and are rapidly becoming essential components of many academic and industrial research laboratories. A wide range of specimens may be examined directly using Micro-CT including mineralized tissues such as teeth, bone, and materials such as ceramics, polymers, biomaterial scaffolds etc. MicroCT imaging could also be extended to soft tissues such as lungs that have been infiltrated or perfused with a contrast agent having a higher density than the surrounding tissue. With the development of Micro-CT systems, the newest generation of such systems allows for in vivo imaging of small live animals (Guldberg et al., 2003; Guldberg et al., 2004).

Micro-CT system using microfocal spot X-ray sources and high resolution detectors, allow for projections rotated through multiple viewing directions to produce $3 \mathrm{D}$ reconstructed images of samples. The images represent spatial distribution maps of linear attenuation coefficients determined by the 
energy of the X-ray source and the atomic composition of the material sample. Since the imaging process is nondestructive, the internal features of the same sample may be examined many times and samples remain available after scanning for additional biological and mechanical testing. MicroCT systems are now widely used in many academic fields, several recent reviews have presented the current state of Micro-CT imaging and analysis of them (Paulus et al., 2000; Bentley et al., 2002; Holdsworth and Thornton, 2002; Guldberg et al., 2003; Guldberg et al., 2004). The purpose of this article is to review recent applications of Micro-CT in dental research.

\section{Enamel thickness and tooth measurement}

Tooth enamel thickness has long been considered to be of importance in anthropological studies and the interpretation of human evolution for its purported taxonomic and phylogenetic value in human evolution. Enamel thickness was also thought to be of significance for the interpretation of occlusal loading regimens. There are several techniques for measuring enamel thickness, including a physical cross-sectional method widely used by a number of researchers. But it was a destructive technique which led to continued controversy and criticism as to whether one should produce sectioned teeth or thin sections, especially of rare, endangered, or extinct fossil specimens. Other problems with this technique like specimen orientation may also render some of such data to be less than ideal. CT had also been utilized to quantify enamel thickness in recent research. However, the low resolution and exaggerated effect of standard CT images makes the data grossly inaccurate. Application of Micro-CT systems has become an effective and nondestructive technique for the measurement of enamel thickness (Olejniczak and Grine, 2005; Olejniczak and Grine, 2006). It has been used to measure enamel thickness of a great variety of archaeological specimens (Olejniczak et al., 2008; Olejniczak et al., 2008; Olejniczak et al., 2008; Smith et al., 2009).

Accuracy of dental enamel thickness measurements for a variety of primates and nonprimates have been compared using physical sectioning of teeth as a control. Both recent and fossil taxa specimen were measured with these two techniques. Results indicated that recent teeth of varying size and thickness were clearly and accurately depicted in Micro-CT scans, with measurements from nearly identical planes in physical and Micro-CT sections differing by only $3 \%-5 \%$ (Olejniczak and Grine, 2006). The accuracy of Micro-CT was also compared to measurements made by direct measurement, 3D scanner and by photography, the results indicated that Micro-CT was a reliable method and might be a useful device for measuring distances and for observing both internal and external tooth structure (Kim et al., 2007). Apart from the enamel thickness, Micro-CT systems could also generate contiguous slices revealing the thickness and area of enamel, dentin, and pulp chamber accurately and reliably. In addition with imaging software, 3D reconstructions could be produced, which also provide volumetric data for enamel and dentin (Gantt et al., 2006). Although Micro-CT is an accurate technique for measuring enamel thickness, however for severely mineralized teeth it may produce a limitation for reliably distinguishing dental tissues. Moreover, very thin enamel regions (less than $100 \mu \mathrm{m})$ are difficult to resolve adequately from raw Micro-CT images based on pixel values alone. Therefore, caution must be exercised in the application of Micro-CT to the study of enamel thickness of fossilized teeth (Olejniczak and Grine, 2006).

\section{Analysis of root canal morphology and evaluation of root canal preparation}

Amongst the great variation and complexity of root canal morphology, there usually exist fins, webbing, accessory canals and multiple foramina. It is very important for an endodontist to develop a complete understanding of the 3D morphologic characteristics of root canal systems and the associated changes during root canal treatment. The best endodontic treatment is soundly based on a thorough background knowledge of the internal anatomy of teeth. However, conventional clinical radiography only produces a $2 \mathrm{D}$ record rather than 3D information of a tooth from radiography. Tradi- 
tional in vitro methods of studying morphologic characteristics of root canal systems are generally destructive and produce irreversible changes to the specimen, such as tooth serial sections, transparent tooth and dye penetration etc. CT provides a noninvasive method to study root canal morphology, whereas conventional CT was hampered mainly by low resolution, which could not produce exact reconstructions with crassus slice thickness. With the availability of Micro-CT systems, root canal morphology could be noninvasively and precisely studied. A large amount of information could be obtained from a Micro-CT scan; slices could be recreated in any plane, and data could be represented as 2D or rendered 3D images. Internal and external anatomy could be demonstrated simultaneously or separately. Images could be assessed qualitatively and quantitatively (Dowker et al., 1997; Rhodes et al., 1999).

\section{Analysis of root canal morphology}

Using Micro-CT it is possible to analyze many aspects of the inner structure of a tooth. Several researchers have used Micro-CT to generate both qualitative and quantitative outcome measures for investigations of pulp cavity and root canal morphology. A study based on 3D observations of pulp cavities of 10 maxillary first premolar tooth indicated that, from scans, using the reconstructed images, the morphological characteristics of the pulp cavity, the volume ratio at the horn, floor and overall regions of the pulp chamber and the diameters of the buccal and lingual orifices of the root canals could be measured and compared between different groups (Oi et al., 2004). Some researchers used Micro-CT to analyze root canal morphology. They found that surface areas and volumes of each root canal could be calculated by triangulation methods, canals' diameters and configuration could be evaluated by model-independent methods. In addition root canal curvature could be measured by creating an imaginary central axis for each canal (Peters, 2000), by calculating the rate of turning of the tangent vector at a given point of the central axis, and inverting this rate to curvature of the canal by special mathematical modeling software (Lee et al., 2006). The different parts of a tooth could be $3 \mathrm{D}$ reconstructed together making the dental hard tissues transparent and the pulp chamber and root canal system opaque, both external and internal morphology of a tooth could be conveniently reconstructed, and the relationship between the external and internal macromorphology of the complex crown and root could be analyzed (Bjorndal et al., 1999). Therefore, data from Micro$\mathrm{CT}$ could serve as a basis for further analysis of root canal anatomy in experimental endodontology, preclinical training in fundamental endodontic procedures, and a valuable mathematical modeling of tooth morphology.

The C-shaped canal was one of the most complex anatomic variations of the canal system, it was mostly found in mandibular second molars and produced many challenging problems with respect to root canal debridement and obturation. Thus it was necessary to clarify the detailed morphologic structure and anatomic variation of such canals (Jafarzadeh and Wu, 2007). The use of Micro-CT systems to study C-shaped canals has generated valuable outcomes. One research group has systematically studied the C-shaped canal system of Chinese mandibular second molars with Micro-CT, including anatomical and radiographic features (Fan et al., 2004), morphology of the pulp chamber floor (Min et al., 2006), 3D morphological analysis and transverse measurements (Gao et al., 2006), apical anatomy (Cheung et al., 2007) root canal shape changes after rotary instrumentation (Cheung and Cheung, 2008), and C-shaped canal systems of mandibular first premolars (Fan et al., 2008). Their results are promising and very helpful for a deeper under- standing of C-shaped canals.

\section{Evaluation of root canal preparation}

Successful endodontic therapies depend on many factors, the most important step being canal preparation. It is essential because the initial preparation determines the efficacy of all subsequent procedures including mechanical debridement, creation of space for medicament delivery, and optimized canal geometries for adequate obturation. However, canal preparation may be adversely influenced by the highly variable root-canal anatomy and the relative inability of the operator to visualize this anatomy from radiographs (Peters, 2004). With the 
progress of the root canal instruments, the efficacy of root canal preparation has been greatly improved, but it is not easy to fully evaluate and compare different instruments performance. However, with the Micro-CT systems, the 3D evaluation of canal preparation has been made easy and convenient (Bergmans et al., 2001). A number of researchers have evaluated and compared different root canal instruments with Micro-CT, including K-files (Peters et al., 2001; Peters et al., 2001), K-flexofiles (Peru et al., 2006), Profile (Bergmans et al., 2001; Peters et al., 2001; Peters et al., 2001; Cheung and Cheung, 2008; Versiani et al., 2008), Protaper (Bergmans et al., 2003; Ozgur Uyanik et al., 2006; Peru et al., 2006; Versiani et al., 2008), Hero Shaper (Ozgur Uyanik et al., 2006; Cheung and Cheung, 2008), System GT (Peters et al., 2001; Peru et al., 2006; Versiani et al., 2008), Lightspeed (Peters et al., 2001; Peters et al., 2001), K3 (Bergmans et al., 2003), Endo-Eze AET (Paque et al., 2005), RaCe (Ozgur Uyanik et al., 2006), and Flexmaster (Hubscher et al., 2003). With the data from such scans, it is possible to measure many changes before and after preparation, such as surface area and volume of root canal, amount of dentin volume removed, canal "thickness" (diameter), prepared surface, curvature, canal transportation, structure model index (SMI), transportation of centers of mass, canal straightening proportion of unchanged, canal centering ratio (Peters et al., 2001; Peters et al., 2001; Peters et al., 2003). According to the results of these researchers, it was believed that variations in canal geometry before preparation have more influence on the changes during preparation than the techniques and instruments themselves (Peters et al., 2001), as nearly all instrumentation techniques left 35\% or more of the canals' surface area unchanged. Furthermore different instrument types demonstrated few differences on the general effect of preparation (Peters et al., 2001), but caused effects at different parts of the same root canal (Bergmans et al., 2003; Peters et al., 2003; Ozgur Uyanik et al., 2006; Peru et al., 2006). The majority of instruments enable easy access and can be manipulated safely with respect to different experience levels of users. However, some researchers have reported that Endo-Eze AET instruments shaped root canals in maxillary molars with substantial canal transportation (Paque et al., 2005), while RaCe files significantly transported the canals at the coronal level (Ozgur Uyanik et al., 2006).

Micro-CT was also used for evaluating effectiveness of instrumentation for retreatment of canals, ProTaper files and hand K-files were used to remove root fillings, and remaining filling volume of different obturation materials was evaluated by Micro-CT. The results indicated that no one tested filling material could be completely removed during retreatment by using hand or rotary files. Gutta-percha was more efficiently removed by hand K-files (Hammad et al., 2008).

\section{Craniofacial skeletal development and structure}

The main application of Micro-CT to date has been the nondestructive analysis of trabecular bone. A high resolution Micro-CT system has also been used in the research of craniofacial skeletal development, structure and measure for investigations of bone growth and repair. Micro-CT imaging of craniofacial bone has facilitated quantitative 3D measurements of trabecular bone morphology parameters such as trabecular thickness (Tb.Th), trabecular number (Tb.N), trabecular separation (Tb.Sp), bone volume (BV), total tissue volume (TV), trabecular bone volume fraction (BV/TV), structure model index (SMI) which quantified the rod-like or plate-like characteristic of 3D trabecular structure, trabecular connectivity, number of nodes per tissue volume (N.Nd/TV) and bone density with respect to standard hydroxyapatite etc (Guldberg et al., 2004). The unique features and wider availability of micro-CT have made it the new gold standard technique for quantifying bone architecture and has stimulated a rapidly growing number of new applications.

One researcher studied architecture and mineralization of developing trabecular bone of pig mandibular mondyle with Micro-CT, the results indicated that the remodeling state of the condyle was different anteriorly and posteriorly, where more active growth took place posteriorly. Bone volume fraction augmented with age by an increase of trabecular thickness while the number of trabeculae declined anteriorly and increased in 
trabecular separation posteriorly. A conversion from rod-like into plate-like trabeculae was observed as expressed by the SMI. The trabecular structure has a clear orientation throughout the developmental process. Bone volume and trabecular thickness were always higher in the corpus. The global degree of mineralization increased both anteriorly and posteriorly, the degrees of mineralization in corpus were higher than in the condyle. The degree of mineralization increased from the surface toward the centers of the trabecular elements, besides apposition of new bone material on the surface of trabeculae, the mineralized tissue in their centers still changed and matured (Mulder et al., 2005; Mulder et al., 2006). Micro-CT was used to assess boron-based antimicrobial effect on experimental periodontitis. Results showed that the experimental periodontitis condition caused a $46 \%$ decrease in bone volume. After treatment the bone volume was $35 \%$ higher with $1 \%$ boron-based antimicrobial and $45 \%$ with ketorolac than the experimental periodontitis group, but there was no significant difference between results with $1 \%$ boron-based antimicrobial and ketorolac $(P>0.05)$. When the data were expressed in terms of bone loss, treatment with $1 \%$ boron-based antimicrobial reduced bone loss by $44 \%$, and ketorolac reduced it by $56 \%$ compared with bone loss in the experimental periodontitis group (Luan et al., 2008).

Another group studied porosity of the human mandibular condylar with Micro-CT. They found that cortical porosity did not differ significantly between different cortical regions, but trabecular bone porosity had a significant negative correlation between surface area of the trabecular and degree of mineralization. They concluded that the amount of remodeling was larger in trabecular than in cortical bone of the mandibular condyle (Renders et al., 2007). Micro-CT has been used to quantitatively investigate periradicular bone destruction. In their experiment, 3D void volume, void surface, and void thickness of bone destruction were analyzed. The results showed a good correlation between lesion void volume and 2D lesion area by histology. The 3D analysis of Micro-CT images is highly correlated with 2D cross-sectional measures of periradicular lesions (von Stechow et al., 2003).

\section{Biomechanics}

In the last four decades, finite element modeling (FEM) has become the prevalent technique used for analyzing physical phenomena in the field of structural, solid and fluid mechanics as well as biomechanics. The use of FEM in biomechanics has received considerable advances both as a research and a teaching tool. Its use in dental research has also been significantly refined during the last decade (Mackerle, 2004; van Staden et al., 2006). As teeth and bones could not be assimilated by a simplified geometric representation but had anatomical shapes and a layered structure, it was better to use the patient's geometry-based meshing algorithms to generate complex solid models of teeth and bones from the CT scan. Similar approaches could be used with Micro-CT scanner to generate a more exact finite element model of small objects like teeth, dental implants and dental restorations.

Using Micro-CT techniques enables a much more precise finite element model of both teeth and bones. After a Micro-CT scan of a tooth, it is possible to segment enamel, dentin and pulp into different parts based on pixel grey level values or mineral density, after which different material properties are assigned along with appropriate boundary conditions, to simulate the variation of strain and stress following cavity preparation and restoration. One author using Micro-CT created a 3D finite element model of human premolar and simulated a cusp-replacing resin composite restoration. The result indicated that the stress patterns were $3 \mathrm{D}$, stress concentrations were found at the surface where the load was applied and in the vicinity of the dentin-composite bonding surface (Verdonschot et al., 2001).

Another study using Micro-CT created an efficient 3D finite element for analysis of dental restorative procedures. The study simulated different cavity preparations (MO/MOD preparations, endodontic access) and restorations (feldspathic porcelain and composite resin inlays) with finite element analysis (FEA). The results showed that the Micro-CT method can generate detailed and valid 3D FEM of teeth and simulated the influence of different treatments on stress distribution (Magne, 
2007). Micro-CT based FEM of bone analysis has become of great interest in recent years, as the advantage of Micro-CT's high resolution and high precision for trabecular imaging, it is widely used in bone FEM. One author studied the mechanical significance of the trabecular microstructure of the human mandibular condyle with Micro-CT, it was found that the trabecular structure was subjected to significant tensile forces and the orientation of the parasagittal strains followed the direction of the applied load. The trabecular structure of the mandibular condyle was optimal in resisting the compressive and tensile strains to which it was subjected (van Ruijven et al., 2002). Another group studied the relationship between partially impacted mandibular third molars and angle fractures with Micro-CT based FEA. The result indicated that $3 \mathrm{D}$ bone microstructure did not show marked differences between mandibles with and without third molars, but FEA showed that the stress would concentrate around the root apex of the third molar if there was a third molar, the stress would then transmit in a direction matching the clinical findings of angle fractures. This suggested that the presence of an impacted third molar changed the concentration and transmission of stress in the mandible, thus increasing the risk of an angle fracture (Takada et al., 2006). In a study on the influence of the bite force on the internal structure of the mandible following a dental implant using Micro-CT based FEA, it indicated that stress distribution was seen in the trabecular bone around the implants, and pressure was transmitted to mandibular internal structures via implants, and stress was dispersed along internal trabecular alignment (Matsunaga et al., 2008).

Another author analyzed stress distribution associated with three nickel-titanium (Ni-Ti) rotary files under bending and torsional conditions with Micro-CT based FEA. The results showed that ProFile had the greatest flexibility, the highest stress was observed at the surface near the cutting edge and the base of flutes during bending. Stress concentration occurred at the bottom of the flute when the instrument was subjected to torsion (Kim et al., 2009).

\section{Tissue engineering}

Tissue engineering is an emerging multidisciplinary field that applies the principles of biology and engineering to the development of viable substitutes that re-create functional, healthy tissues and organs in order to replace diseased, dying or dead tissues. The goal of tissue engineering research is for bio-artificial organs to be grown in a laboratory and subsequently transplanted into people, potentially providing a permanent and specific cure. As tissue engineering relates to the oralmaxillofacial apparatus, hard and soft tissue defects secondary outcomes of trauma (e.g, car accidents), congenital defects (e.g., cleft palate), and acquired diseases (e.g., cancer, periodontal disease) are a significant health problem (Kaigler and Mooney, 2001). In the research field of tissue engineering, scaffold material and porous architecture design plays a significant role in tissue regeneration by preserving tissue volume, providing temporary mechanical functions, and delivering biofactors (Hollister et al., 2005). Micro-CT has been used in the study of scaffolds for tissue engineering in recent years, and has mainly been used for characterizing scaffold architecture, in vitro scaffold degradation, and bone growth into polymeric and calcium phosphate scaffolds (Cartmell et al., 2004). The 3D data sets obtained using Micro-CT provides more accurate information on the structure of the sample than complementary 2D methods.

One author studied bone density increase and mineralization effects of calvarial-derived osteoblasts and adipose-derived stromal (ADS) cells on healing mouse calvarial defects. Micro-CT imaging result showed that, in a calvarial-derived osteoblasts group, radiopacity of the defect area increased over time, and at 8 weeks new bone reached $90 \%$ of the radiopacity of normal bone. In ADS cells group, after only 4 weeks, radiopacity of the defect area equaled $90 \%$ that of normal bone; at 12 weeks, radiopacity had exceeded $20 \%$ of the normal bone. These results indicated that these two cells had good mineralization potential for bone defect healing (Cowan et al., 2004). Another group studied structural and mechanical evaluation of craniofacial scaffolds with Micro-CT. Their experiments indicated that one could examine how well the actual 
fabricated scaffold structure replicates the design structure after a Micro-CT scan, as the original scaffold design was defined by image voxels. The Micro-CT scan could also be used to assess structural changes during degradation, pinpointing precisely where material was lost (Hollister et al., 2005).

\section{Mineral concentrations of teeth}

Mineral concentration distributions or mineral densities in dental hard tissues can be measured either by direct (e.g., chemical analysis of a microsample), or indirect methods (e.g., contact microradiography) (Wong et al., 2004). However, these techniques were more or less destructive and time consuming in sample preparation. In recent years, Micro-CT system has been developed to quantitatively measure the mineral concentration of bones and teeth with an accuracy of better than 1\% and a resolution between 5 and $30 \mu \mathrm{m}$. The advantage of Micro-CT scanning being that it is a non-destructive method and the slice thickness is constant, and irregularities due to physical cutting can be avoided. Furthermore, the minimum slice thickness only depends on the size of the X-ray beam, so Micro-CT slices can be much thinner than those sliced using a cutting machine (Davis and Wong, 1996). Micro-CT has become more and more popular for the analysis of mineral concentrations of teeth.

In the field of mineral concentration of dental hard tissues, one research group has done a considerable amount of study. They firstly used Micro-CT to measure linear attenuation coefficients of a human premolar. The result showed enamel was $13.4 \mathrm{~cm}^{-1}$ and dentin ranged from 6.5 to $7.4 \mathrm{~cm}^{-1}$ (Elliott, 1989). A study comparing mineral content of enamel and dentin of premolars and enamel pearls by Micro-CT showed that the mineral content gradient in the pearls, reduced from the enamel surface to the amelodentinal junction (ADJ) found that the mineral contents in surface and deeper enamel regions of the pearl were similar to those observed in premolar enamel. In contrast, the mineral content for the dentin of the pearl was greatest at the ADJ. These results suggested that the process of mineralization at the pearl dentin differs from that of permanent coronal dentin (Anderson et al., 1996). Their research on the extent of variations in enamel density in first permanent molars with idiopathic enamel hypomineralization showed that, there was a $20 \%$ reduction in mineral concentration of affected enamel, and hypomineralized enamel had a mineral concentration gradient opposite to that of normal enamel. In addition regions of hypomineralization were distributed randomly throughout affected teeth (Fearne et al., 2004). Concerning an evaluation of the mineral concentration distribution in deciduous enamel, they found that the mean mineral density of the tested teeth was $2.81 \mathrm{~g} \cdot \mathrm{cm}^{-3}$ (S.D.= $\left.0.065 \mathrm{~g} \cdot \mathrm{cm}^{-3}\right)$. There was no observable difference in the mean mineral concentration values between the three slices (taken at 1.5, 2.0 and $2.5 \mathrm{~mm}$ from the ADJ) of each tooth. However, there was up to an $8 \%$ variation between different teeth $(2.69$ $\left.2.92 \mathrm{~g} \cdot \mathrm{cm}^{-3}\right)$. Gradients of increasing mineral concentration from the ADJ to the external surface were found, ranging from 0.08 to $0.60 \mathrm{mg} \cdot \mathrm{cm}^{-3} \cdot \mu \mathrm{m}^{-1}$ with a mean of $0.366 \mathrm{mg} \cdot \mathrm{cm}^{-3} \cdot \mu \mathrm{m}^{-1}$. The mineral concentration gradients in the occlusal slices were steeper than those in the cervical slices. The difference in mineral concentration between inner and outer enamel ranged from $1.5 \%$ to $8.7 \%$ (Wong et al., 2004). Another investigation of mineral concentrations at the micron scale in sound and carious enamel indicated that, quantitative measurements of mineral concentration derived from linear attenuation coefficient (LAC) were consistent with previous measurements of sound and carious enamel from microradiographic projections. However, though mineral concentration could be determined from LAC with an error of $<0.2 \mathrm{~g} \cdot \mathrm{cm}^{-3}$, the variation in pore fraction volume within caries lesions could not be reliably determined from X-ray attenuation measurements alone (Dowker et al., 2004). Using the non-destructive characteristics of Micro-CT, they quantitatively showed how much mineral was lost after demineralization in the enamel of a tooth rod, and how much mineral was regained after remineralization (in the same position of the same rod) (Gao, 1993). A study of the effect of pumicing and etching on the remineralization of enamel opacities by MicroCT showed that the treatment removed $(34 \pm 4) \mu \mathrm{m}$ from the surface enamel but no mineral loss was 
observed in the subsurface layer. The treatment sequence enhanced the formation of a new less $\mathrm{X}$-ray reflective remineralized surface layer with a mean thickness of $(22 \pm 3) \mu \mathrm{m}$ (Peariasamy et al., 2001). Another study of the 3D development of subsurface enamel lesions in human molars during a longer term demineralization (ranging from 36107 days) through $\sim 1$-mm-wide windows showed that the distribution of mineral in the most superficial region varied across the exposed face of each lesion, whereas within lesions localized foci of low mineral concentration retained their general form through successive stages of demineralization before coalescing. Local variations in fractional pore volume of partially demineralized enamel influence the subsequent spatial development of lesions (Dowker et al., 2003).

Another research group has conducted research with Micro-CT on the demineralization effect of teeth bleaching with carbamide peroxide. They applied both $10 \%$ and $35 \%$ carbamide peroxide bleaching agents on human teeth for different times. Their results showed that the application of $10 \%$ carbamide peroxide caused demineralization of the enamel extended to a depth of $50 \mu \mathrm{m}$ below the enamel surface. Whereas when application of $35 \%$ carbamide peroxide occurred, there was a significant reduction in the mineral content of enamel specimens postbleach application extending to a depth of $250 \mu \mathrm{m}$, mineral content reduction was greatest in the area closest to the tooth surface. However, no significant difference was found in the mineral content of dentin as a consequence of bleaching (Efeoglu et al., 2005; Efeoglu et al., 2007).

Micro-CT has been used to characterize mineral density of enamel white spot lesions and dentin caries. The results indicated that the mineral density of sound enamel, apparent intact surface layer of white spot lesion, and lowest level of white spot lesion was found to be 2.65-2.89, $2.23-2.58$ and $1.48-2.03 \mathrm{~g} \cdot \mathrm{cm}^{-3}$, respectively with five different hydroxyapatite phantoms (densities ranging from 1.52 to $3.14 \mathrm{~g} \cdot \mathrm{cm}^{-3}$ ) used as calibration standards for each Micro-CT scan (Huang et al., 2007). For mineral density of sound dentin and carious dentin, it was suggested that the contribution of water and organic material within dentin be taken into account. To calibrate mineral density from polychromatic Micro-CT investigations, a new two-phase calibration method was proposed to expand the calibration curve obtained from water solutions at different concentrations of $\mathrm{K}_{2} \mathrm{HPO}_{4}$ by using a second set of standards, prepared by vacuum-assisted infiltration of water into solid homogeneous porous hydroxyapatite (HA) phantoms with different densities. The new materials with similar composition to dentin and covering a representative range of mineral densities (Zou et al., 2009). In a study on the effect of vitamin $\mathrm{D}$ on mouse enamel and dentin mineralization, Micro-CT was able to detect the different distribution patterns of enamel and dentin mineral density between vitamin D receptor (VDR) and VDR deficient groups (Zhang et al., 2009). Micro$\mathrm{CT}$ is a very sensitive in vitro technique and is capable of characterizing and quantifying mineral densities of sound enamel, dentin and carious enamel, dentin. This method has a promising potential for future caries and quantitative remineralization studies.

\section{Implant and periimplant bone}

In implant dentistry, the measurement of implant stability and osseointegration is important to assess the success of treatment. The stability of an implant is determined by the mechanical properties of the implant-bone interface and the quality of the fixation between the implant surface and bone. The osseointegration of the interface has been commonly evaluated by histomorphometric analysis. However, histomorphometry is a destructive method, and the same specimen could not be used for other characterizations such as a removal torque force measurement. Another disadvantage of histomorphometric analysis is that only a few sections per implant could be obtained via grindingsectioning methods, the procedures of sample preparation often result in artifacts. Micro-CT is a nondestructive, fast, and precise technique that allows measurements of trabecular and cortical bone. It can provide a spatial representation of bone formation at the implant surface and the periimplant region up to a few microns or even better, and can evaluate both qualitative and quantitative morphometry of bone integration about 
dental implants (Park et al., 2005).

Titanium, which is a widely used material for load bearing implants, exhibits much stronger X-ray absorption than bone. During CT scanning, as titanium absorbs and scatters X-ray energy at various rates, it often causes inherent halation artifacts, which are called "partial volume effects". Partial volume effects will influence Micro-CT imaging and parameters associated with calculating bone density about an implant surface (Butz et al., 2006).

The use of Micro-CT in implant and periimplant bone research has been popular for the past decade, many authors have studied the implant (Schicho et al., 2007), periimplant bone (Rebaudi et al., 2004; Kim et al., 2008; Yoo et al., 2008; Freilich et al., 2009), interface osseointegration and bone-implant integration with the Micro-CT technique (van Oossterwyck et al., 2000; Sennerby et al., 2001; Butz et al., 2006; Morinaga et al., 2008), and have obtained some meaningful results. From Micro-CT scans, one may determine parameters of periimplant bone like bone volume (BV), bone surface (BS), trabecular thickness (Tb.Th), trabecular separation (Tb.Sp), bone connectivity and bone implant integration etc, . The image slices may be reconstructed in an arbitrary plane and imported into image analyzing software to generate semiautomatic quantitative measurement of the bone area. Accuracy of Micro-CT was qualitatively evaluated by comparing to standard histomorphometric data with the corresponding CT slices for the same specimen. The results showed that, in general there was a good correlation between histomorphometric data and microtomographic data. One author obtained a correlation coefficient of 0.855 (Park et al., 2005), another reported the correlation coefficient of 0.65 for cortical bone and 0.92 for cancellous bone. However, there was no obvious correlation in the area of the near surface of the implant, as the titanium halation artifact due to the partial volume effect would occur within 2 voxels (the exact distance depend on resolution) from the implant surface. Thus, within 2 voxels of the implant surface, BV/TV values may have been overestimated using Micro-CT (Butz et al., 2006). Furthermore, as the complete digital data on the trabecular bone structure around the implant is available, it is possible to create finite-element models of the bone-implant system that model the trabeculae in detail so that mechanical stress transfer at the interface can be studied at the level of individual trabeculae (van Oossterwyck et al., 2000). In the area of the application of Micro-CT in implant dentistry, further research is required to increase accuracy and reduce inherent metallic halation artifacts of bone implant integration assessment.

\section{Summary}

Micro-CT analysis has proven useful in a wide variety of applications in dental research. It can provide high-resolution images as well as both qualitative and quantitative analysis of tooth, bone and implants. With further development of MicroCT systems, higher resolution will become available for both in vitro and in vivo studies, and it will be a powerful tool in future dental research.

\section{References}

Anderson P, Elliott JC, Bose U, Jones SJ (1996). A comparison of the mineral content of enamel and dentine in human premolars and enamel pearls measured by X-ray microtomography. Arch Oral Biol, 41(3): 281-290.

Bentley MD, Ortiz MC, Ritman EL, Romero JC (2002). The use of microcomputed tomography to study microvasculature in small rodents. Am J Physiol Regul Integr Comp Physiol, 282(5): 1267-1279.

Bergmans L, van Cleynenbreugel J, Beullens M, Wevers M, van Meerbeek B, Lambrechts P (2003). Progressive versus constant tapered shaft design using NiTi rotary instruments. Int Endod J, 36(4): 288-295.

Bergmans L, van Cleynenbreugel J, Wevers M, Lambrechts P (2001). A methodology for quantitative evaluation of root canal instrumentation using microcomputed tomography. Int Endod J, 34(5): 390-398.

Bjorndal L, Carlsen O, Thuesen G, Darvann T, Kreiborg S (1999). External and internal macromorphology in 3D-reconstructed maxillary molars using computerized X-ray microtomography. Int Endod J, 32(1): 3-9.

Butz F, Ogawa T, Chang TL, Nishimura I (2006). Threedimensional bone-implant integration profiling using micro-computed tomography. Int J Oral Maxillofac Implants, 21(5): 687-695.

Cartmell S, Huynh K, Lin A, Nagaraja S, Guldberg R (2004). Quantitative microcomputed tomography ana- 
lysis of mineralization within three-dimensional scaffolds in vitro. J Biomed Mater Res A, 69(1): 97-104.

Cheung GS, Yang J, Fan B (2007). Morphometric study of the apical anatomy of C-shaped root canal systems in mandibular second molars. Int Endod J, 40(4): 239-246.

Cheung LHM, Cheung GSP (2008). Evaluation of a rotary instrumentation method for C-shaped canals with micro-computed tomography. J Endod, 34(10): 12331238.

Cowan CM, Shi YY, Aalami OO, Chou YF, Mari C, Thomas R, et al. (2004). Adipose-derived adult stromal cells heal critical-size mouse calvarial defects. Nat Biotechnol, 22(5): 560-567.

Davis GR, Wong FS (1996). X-ray microtomography of bones and teeth. Physiol Meas, 17(3): 121-146.

Dowker SE, Davis GR, Elliott JC (1997). X-ray microtomography: nondestructive three-dimensional imaging for in vitro endodontic studies. Oral Surg Oral Med Oral Pathol Oral Radiol Endod, 83(4): 510-516.

Dowker SE, Elliott JC, Davis GR, Wassif HS (2003). Longitudinal study of the three-dimensional development of subsurface enamel lesions during in vitro demineralisation. Caries Res, 37(4): 237-245.

Dowker SE, Elliott JC, Davis GR, Wilson RM, Cloetens P (2004). Synchrotron X-ray microtomographic investigation of mineral concentrations at micrometre scale in sound and carious enamel. Caries Res, 38(6): 514-522.

Dunn PM (2001). Wilhelm Conrad Roentgen (1845-1923), the discovery of $\mathrm{X}$ rays and perinatal diagnosis. Arch Dis Child Fetal Neonatal Ed, 84(2): 138-139.

Efeoglu N, Wood D, Efeoglu C (2005). Microcomputerised tomography evaluation of $10 \%$ carbamide peroxide applied to enamel. J Dent, 33(7): 561-567.

Efeoglu N, Wood DJ, Efeoglu C (2007). Thirty-five percent carbamide peroxide application causes in vitro demineralization of enamel. Dent Mater, 23(7): 900-904.

Elliott JC, Anderson P, Davis G, Dover SD (1989). Enamel, $\mathrm{V}$ ed. In: Fearnhead RW ed, Application of X-ray microtomography to the study of dental hard tissues. Yokahama: Florence, pp.429-433.

Fan B, Cheung GS, Fan M, Gutmann JL, Bian Z (2004). $\mathrm{C}$-shaped canal system in mandibular second molars: Part I -Anatomical features. J Endod, 30(12): 899903.

Fan B, Cheung GS, Fan M, Gutmann JL, Fan W (2004). C-shaped canal system in mandibular second molars: Part II -Radiographic features. J Endod, 30(12): 904908.

Fan B, Yang J, Gutmann JL, Fan M (2008). Root canal systems in mandibular first premolars with $\mathrm{C}$-shaped root configurations. Part I : Microcomputed tomography mapping of the radicular groove and associated root canal cross-sections. J Endod, 34(11): 1337-1341.
Fearne J, Anderson P, Davis GR (2004). 3D X-ray microscopic study of the extent of variations in enamel density in first permanent molars with idiopathic enamel hypomineralisation. Br Dent J, 196(10): 634-638.

Feldkamp LA, Goldstein SA, Parfitt AM, Jesion G, Kleerekoper M (1989). The direct examination of threedimensional bone architecture in vitro by computed tomography. J Bone Miner Res, 4(1): 3-11.

Freilich M, Shafer D, Wei M, Kompalli R, Adams D, Kuhn L (2009). Implant system for guiding a new layer of bone. Computed microtomography and histomorphometric analysis in the rabbit mandible. Clin Oral Implants Res, 20(2): 201-207.

Gantt DG, Kappleman J, Ketcham RA, Alder ME, Deahl TH (2006). Three-dimensional reconstruction of enamel thickness and volume in humans and hominoids. Eur $J$ Oral Sci, 114 (Suppl 1): 360-364, 375-376, 382-383.

Gao XJ, Anderson P, Davis GR (1993). Scanning microradiographic and microtomographic studies of remineralization of subsurface enamel lesions. J Chem Soc (Faraday Transactions), 89: 2907- 2912.

Gao Y, Fan B, Cheung GS, Gutmann JL, Fan M (2006). $\mathrm{C}$-shaped canal system in mandibular second molars: Part IV-3D morphological analysis and transverse measurement. J Endod, 32(11): 1062-1065.

Guldberg RE, Ballock RT, Boyan BD, Duvall CL, Lin AS, Nagaraja S, et al. (2003). Analyzing bone, blood vessels, and biomaterials with microcomputed tomography. IEEE Eng Med Biol Mag, 22(5): 77-83.

Guldberg RE, Lin AS, Coleman R, Robertson G, Duvall C (2004). Microcomputed tomography imaging of skeletal development and growth. Birth Defects Res C Embryo Today, 72(3): 250-259.

Hammad M, Qualtrough A, Silikas N (2008). Threedimensional evaluation of effectiveness of hand and rotary instrumentation for retreatment of canals filled with different materials. $J$ Endod, 34(11): 1370-1373.

Holdsworth DW, Thornton MM (2002). Micro-CT in small animal and specimen imaging. Trends Biotechnol, 20(8): 34-39.

Hollister SJ, Lin CY, Saito E, Lin CY, Schek RD, Taboas $\mathrm{JM}$, et al. (2005). Engineering craniofacial scaffolds. Orthod Craniofac Res, 8(3): 162-173.

Hounsfield GN (1973). Computerized transverse axial scanning (tomography). 1. Description of system. $\mathrm{Br} \mathrm{J}$ Radiol, 46(552): 1016-1022.

Huang TTY, Jones AS, He LH, Darendeliler MA, Swain MV (2007). Characterisation of enamel white spot lesions using X-ray micro-tomography. J Dent, 35(9): 737-743.

Hubscher W, Barbakow F, Peters OA (2003). Root-canal preparation with FlexMaster: canal shapes analysed by micro-computed tomography. Int Endod J, 36(11): 
$740-747$

Jafarzadeh H, Wu YN (2007). The C-shaped root canal configuration: a review. J Endod, 33(5): 517-523.

Kaigler D, Mooney D (2001). Tissue engineering's impact on dentistry. J Dent Educ, 65(5): 456-462.

Kim I, Paik KS, Lee SP (2007). Quantitative evaluation of the accuracy of micro-computed tomography in tooth measurement. Clin Anat, 20(1): 27-34.

Kim SH, Choi BH, Li J, Kim HS, Ko CY, Jeong SM, et al. (2008). Peri-implant bone reactions at delayed and immediately loaded implants: an experimental study. Oral Surg Oral Med Oral Pathol Oral Radiol Endod, 105(2): 144-148.

Kim TO, Cheung GS, Lee JM, Kim BM, Hur B, Kim HC (2009). Stress distribution of three NiTi rotary files under bending and torsional conditions using a mathematic analysis. Int Endod J, 42(1): 14-21.

Kuhn JL, Goldstein SA, Feldkamp LA, Goulet RW, Jesion G (1990). Evaluation of a microcomputed tomography system to study trabecular bone structure. $J$ Orthop Res, 8(6): 833-842.

Lee JK, Ha BH, Choi JH, Heo SM, Perinpanayagam H (2006). Quantitative three-dimensional analysis of root canal curvature in maxillary first molars using microcomputed tomography. J Endod, 32(10): 941-945.

Luan Q, Desta T, Chehab L, Sanders VJ, Plattner J, Graves DT (2008). Inhibition of experimental periodontitis by a topical boron-based antimicrobial. J Dent Res, 87(2): 148.

Mackerle J (2004). Finite element modelling and simulations in dentistry: a bibliography 1990-2003. Comput Methods Biomech Biomed Engin, 7(5): 277-303.

Magne P (2007). Efficient 3D finite element analysis of dental restorative procedures using micro-CT data. Dent Mater, 23(5): 539-548.

Matsunaga S, Okudera H, Abe S, Tamatsu Y, Hashimoto M, Ide Y (2008). The influence of bite force on the internal structure of the mandible through implant three-dimensional and mechanical analysis using micro-CT and finite element method? J Oral Biosci, 50(3): 194-199.

Min Y, Fan B, Cheung GS, Gutmann JL, Fan M (2006). C-shaped canal system in mandibular second molars: Part III-The morphology of the pulp chamber floor. J Endod, 32(12): 1155-1159.

Morinaga K, Kido H, Sato A, Watazu A, Matsuura M (2008). Chronological changes in the ultrastructure of titanium-bone interfaces: analysis by light microscopy, transmission electron microscopy, and micro-computed tomography. Clin Implant Dent Relat Res, 11(1): 59-68.

Mulder L, Koolstra JH, de Jonge HW, van Eijden TM (2006). Architecture and mineralization of developing cortical and trabecular bone of the mandible. Anat
Embryol (Berl), 211(1): 71-78.

Mulder L, Koolstra JH, Weijs WA, van Eijden TM (2005). Architecture and mineralization of developing trabecular bone in the pig mandibular condyle. Anat Rec $A$ Discov Mol Cell Evol Biol, 285(1): 659-666.

Oi T, Saka H, Ide Y (2004). Three-dimensional observation of pulp cavities in the maxillary first premolar tooth using micro-CT. Int Endod J, 37(1): 46-51.

Olejniczak AJ, Grine FE (2005). High-resolution measurement of Neandertal tooth enamel thickness by micro-focal computed tomography. S Afr J Sci, 101(5/6): 219-220.

Olejniczak AJ, Grine FE (2006). Assessment of the accuracy of dental enamel thickness measurements using microfocal X-ray computed tomography. Anat Rec A Discov Mol Cell Evol Biol, 288(3): 263-275.

Olejniczak AJ, Smith TM, Skinner MM, Grine FE, Feeney RNM, Thackeray JF, et al. (2008). Three-dimensional molar enamel distribution and thickness in Australopithecus and Paranthropus. Biol Lett, 4(4): 406-410.

Olejniczak AJ, Smith TM, Wang W, Potts R, Ciochon R, Kullmer O, et al. (2008). Molar enamel thickness and dentine horn. Am J Phys Anthropol, 135: 85-91.

Olejniczak AJ, Tafforeau P, Feeney RNM, Martin LB (2008). Three-dimensional primate molar enamel thickness. J Hum Evol, 54(2): 187-195.

Ozgur Uyanik M, Cehreli ZC, Ozgen Mocan B, Tasman Dagli F (2006). Comparative evaluation of three nickeltitanium instrumentation systems in human teeth using computed tomography. J Endod, 32(7): 668-671.

Paque F, Barbakow F, Peters OA (2005). Root canal preparation with Endo-Eze AET: changes in root canal shape assessed by micro-computed tomography. Int Endod J, 38(7): 456-464.

Park YS, Yi KY, Lee IS, Jung YC (2005). Correlation between microtomography and histomorphometry for assessment of implant osseointegration. Clin Oral Implants Res, 16(2): 156-160.

Paulus MJ, Gleason SS, Kennel SJ, Hunsicker PR, Johnson DK (2000). High resolution X-ray computed tomography: an emerging tool for small animal cancer research. Neoplasia, 2(1/2): 62-70.

Peariasamy K, Anderson P, Brook AH (2001). A quantitative study of the effect of pumicing and etching on the remineralisation of enamel opacities. Int J Paediatr Dent, 11(3): 193-200.

Peru M, Peru C, Mannocci F, Sherriff M, Buchanan LS, Pitt Ford TR (2006). Hand and nickel-titanium root canal instrumentation performed by dental students: a micro-computed tomographic study. Eur J Dent Educ, 10(1): 52-59.

Peters OA (2000). Three-dimensional analysis of root canal geometry by high-resolution computed tomography. $J$ Dent Res, 79(6): 1405-1409. 
Peters OA (2004). Current challenges and concepts in the preparation of root canal systems: a review. J Endod, 30(8): 559-567.

Peters OA, Laib A, Gohring TN, Barbakow F (2001). Changes in root canal geometry after preparation assessed by high-resolution computed tomography. $J$ Endod, 27(1): 1-6.

Peters OA, Peters CI, Schonenberger K, Barbakow F (2003). ProTaper rotary root canal preparation: effects of canal anatomy on final shape analysed by micro CT. Int Endod J, 36(2): 86-92.

Peters OA, Schonenberger K, Laib A (2001). Effects of four $\mathrm{Ni}-\mathrm{Ti}$ preparation techniques on root canal geometry assessed by micro computed tomography. Int Endod J, 34(3): 221-230.

Rebaudi A, Koller B, Laib A, Trisi P (2004). Microcomputed tomographic analysis of the peri-implant bone. Int J Periodontics Restorative Dent, 24(4): 316-325.

Renders GA, Mulder L, van Ruijven LJ, van Eijden TM (2007). Porosity of human mandibular condylar bone. $J$ Anat, 210(3): 239-248.

Rhodes JS, Ford TR, Lynch JA, Liepins PJ, Curtis RV (1999). Micro-computed tomography: a new tool for experimental endodontology. Int Endod J, 32(3): 165170.

Schicho K, Kastner J, Klingesberger R, Seemann R, Enislidis G, Undt G, et al. (2007). Surface area analysis of dental implants using micro-computed tomography. Clin Oral Implants Res, 18(4): 459-464.

Sennerby L, Wennerberg A, Pasop F (2001). A new microtomographic technique for non-invasive evaluation of the bone structure around implants. Clin Oral Implants Res, 12(1): 91-94.

Smith TM, Harvati K, Olejniczak AJ, Reid DJ, Hublin JJ, Panagopoulou E (2009). Brief communication: dental development and enamel thickness in the Lakonis Neanderthal molar. Am J Phys Anthropol, 138(1): 112-118.

Takada H, Abe S, Tamatsu Y, Mitarashi S, Saka HIde Y (2006). Three-dimensional bone microstructures of the mandibular angle using micro-CT and finite element analysis: relationship between partially impacted mandibular third molars and angle fractures. Dent Traumatol, 22(1): 18-24. van Oossterwyck H, Duyck J, Vander Sloten J, van der Perre G, Jansen J, Wevers M, et al. (2000). Use of microfocus computerized tomography as a new technique for characterizing bone tissue around oral implants. J Oral Implantol, 26(1): 5-12.

van Ruijven LJ, Giesen EB, van Eijden TM (2002). Mechanical significance of the trabecular microstructure of the human mandibular condyle. $J$ Dent Res, 81(10): 706-710.

Van Staden RC, Guan H, Loo YC (2006). Application of the finite element method in dental implant research. Comput Methods Biomech Biomed Engin, 9(4): 257270.

Verdonschot N, Fennis WM, Kuijs RH, Stolk J, Kreulen CM, Creugers NH (2001). Generation of 3D finite element models of restored human teeth using microCT techniques. Int J Prosthodont, 14(4): 310-315.

Versiani MA, Pascon EA, Alves de Sousa CJ, Borges MAG, Sousa-Neto MD (2008). Influence of shaft design on the shaping ability of 3 nickel-titanium rotary systems by means of spiral computerized tomography. Oral Surg Oral Med Oral Pathol Oral Radiol Endod, 105(6): 807.

von Stechow D, Balto K, Stashenko P, Muller R (2003). Three-dimensional quantitation of periradicular bone destruction by micro-computed tomography. J Endod, 29(4): 252-256.

Wong FS, Anderson P, Fan H, Davis GR (2004). X-ray microtomographic study of mineral concentration distribution in deciduous enamel. Arch Oral Biol, 49(11): 937-944.

Yoo JH, Choi BH, Li J, Kim HS, Ko CY, Xuan F, et al. (2008). Influence of premature exposure of implants on early crestal bone loss: an experimental study in dogs. Oral Surg Oral Med Oral Pathol Oral Radiol Endod, 105(6): 702-706.

Zhang X, Rahemtulla F, Zhang P, Beck P, Thomas HF (2009). Different enamel and dentin mineralization observed in VDR deficient mouse model. Arch Oral Biol, 54(4): 299-305.

Zou W, Gao J, Jones AS, Hunter N, Swain MV (2009). Characterization of a novel calibration method for mineral density determination of dentine by X-ray micro-tomography. Analyst, 134(1): 72-79.

\footnotetext{
*Corresponding author: Jing Xue
}

Address: Biomaterial research Lab, Faculty of Dentistry, The University of Sydney, 2 Chalmers St., Surry Hills, NSW 2010, Australia

Tel: +61293518357Ｅ-mail: jingxue.scu@gmail.com 